\title{
Reference ranges of T lymphocyte subsets by single-platform among healthy population in southwest China
}

Bin Wei ${ }^{1 \dagger}$, Ying Guo ${ }^{2 \dagger}$, Liangjun Zhang ${ }^{3}$, Huixiu Zhong ${ }^{3}$, Qiang Miao ${ }^{1}$, Lin Yan ${ }^{1}$, Yangjuan Bai ${ }^{1}$, Weihua Feng ${ }^{1}$, Weiping Liu ${ }^{3^{*}}$, Qian Niu ${ }^{1^{*}}$ and $\mathrm{Yi} \mathrm{Li}^{i^{*}}$

\begin{abstract}
Background: Appropriate reference ranges of T lymphocyte subsets are essential for immune status evaluation of patients with immunological diseases. We aim to establish the age- and sex-related reference intervals of T lymphocyte subsets by single-platform for the southwest China population using the indirect method with the data resulting from 53,822 cases of periodic health examination individuals in the Laboratory Information System (LIS) of West China Hospital from 2018 to 2020.

Methods: We used the Box-Cox conversion combined with the Tukey method to normalize the data and eliminate the outliers, and the nonparametric method to estimate the $95 \%$ distribution reference intervals.

Results: We initially established the reference ranges of T lymphocyte subsets by single-platform among healthy population in southwest China by indirect method (See text for details). Using the standard normal deviate test (z-test) suggested by Harris and Boyd according to CLSI EP28-A3C, which is more scientific, we found the reference ranges of T lymphocyte subsets should be differentiated by ages and genders since the reference ranges of T lymphocyte subsets by single-platform in different ages and genders are significantly different.

Conclusions: We further demonstrated the absolute count of CD3 $+T$ cell, $C D 3+C D 4+T$ cell, $C D 3+C D 8+T$ cell decreased with aging, which is more marked in men and CD3 + CD8 + T cell count, and the obtained reference intervals were superior to the reference intervals derived from the reagent specification currently in use.
\end{abstract}

Keywords: Reference ranges, T lymphocyte subsets, Single-platform, Southwest China, Indirect method

*Correspondence: liuweiping_1111@163.com; niuqian991@126.com; liyiscu@126.com

${ }^{\dagger}$ Bin Wei and Ying Guo contribute equally to this work and co-first authors.

${ }^{1}$ Department of Laboratory Medicine/Clinical Research Center of Laboratory Medicine, West China Hospital, Sichuan University, 37 Guo Xue Xiang, Chengdu 610041, Sichuan Province, China

${ }^{3}$ Department of Laboratory Medicine, Zigong First People's Hospital, Zigong, Sichuan Province, China

Full list of author information is available at the end of the article

\section{Introduction}

$\mathrm{T}$ lymphocytes (also called $\mathrm{T}$ cells) have many functions, including the establishment and maintenance of immune responses, homeostasis, and memory in human body [1]. Meanwhile, $\mathrm{T}$ cells coordinate multiple aspects of adaptive immunity, playing a crucial role in pathogen elimination and tumor surveillance [1-3]. Specific subsets of $\mathrm{T}$ cells control this process to keep the immune system in check and prevent autoimmunity. For instance, low $\mathrm{CD} 4+\mathrm{T}$ cell counts and CD4/CD8 ratio were independent unfavorable prognostic predictors for patients with multiple myeloma, waldenstrom macroglobulinemia and 
mantle cell lymphoma patients at diagnosis [4-7]. Multiple Sclerosis patients have lower proportion of $\mathrm{CD} 3+\mathrm{T}$ cells and $\mathrm{CD} 4+\mathrm{T}$ cells than healthy subjects according to Arneth B's research [8]. To our knowledge, the hall mark of human immunodeficiency virus (HIV) infection is a gradual loss of CD4+ T cells and imbalance in $\mathrm{CD} 4+\mathrm{T}$ cell homeostasis. The peripheral CD4 $+\mathrm{T}$ cells count have served as a biomarker for HIV's immune suppression and response to treatment [9], predicting tumor infiltration and clinical response [10]. Low CD8 + T cell counts are associated with increased AIDS-related mortality and marked elevations in CD8 $+\mathrm{T}$ cell counts after long-term combination antiretroviral therapy are associated with increased non-AIDS-related mortality [11]. Consequently, appropriate reference ranges of $\mathrm{T}$ lymphocyte subsets are essential for immune status evaluation of patients with immunological diseases.

Immunophenotyping of peripheral $\mathrm{T}$ lymphocyte subsets with monoclonal antibodies via flow cytometry which is a rapid and accurate method for identification of peripheral $\mathrm{T}$ lymphocyte subsets has proven to be a useful tool to assess immune status of patients with immunodeficiency, autoimmunity, transplantation, tumor, or infection [10,12-14]. Nevertheless, there are no universal reference ranges of peripheral $\mathrm{T}$ lymphocyte subsets currently on account of distinct regions, ages, genders and ethnic groups, which results in most laboratories using the reference ranges provided by reagent manuals. Meanwhile, the previous $\mathrm{T}$ lymphocyte subsets absolute count reference intervals in China were mainly established by dual-platform, which multiplies the flow cytometry-derived T-cell percentage by the absolute lymphocyte count derived from a hematology analyzer to calculate the absolute count. Previous studies reported that using of the bead-based singleplatform counting methods significantly reduced interlaboratory variation in absolute cell counts compared to predicate dual-platform methods. With the increasing application of single-platform for lymphocyte counts in clinical laboratory, the reference intervals for single-platform is needed. According to the CLSI EP28A3C published by The Clinical and Laboratory Standards Institute, each laboratory should establish its own reference intervals [15]. Few studies have concentrated on the reference ranges of peripheral $\mathrm{T}$ lymphocyte subsets, which have been varied across previous studies potentially resulting from differences in age, gender, ethnicity, and environmental factors [16-18]. In China, in spite several studies have focused on different age- and sex-related reference intervals of lymphocyte subsets [19-23], their sample sizes are limited and no researches have been reported in southwest China. Our laboratory currently uses the reference intervals recommended by the reagent manual. Therefore, it is necessary to establish the reference ranges of $\mathrm{T}$ lymphocyte subsets by single-platform among healthy population in southwest China.

The indirect method based on the assumption, confirmed by observation, that most results, even on hospital and clinic patients, appear "normal" [15]. It uses mathematical-statistical models to analysis the existing data in the hospital database such as laboratory information systems (LIS) to establish biological reference intervals $[15,24]$. In recent years, many scholars have reported researches on reference ranges of laboratory indicators using this method $[24,25]$. Nevertheless, it is rare to use this method to analyze the reference intervals of $\mathrm{T}$ lymphocyte subsets, especially in southwest China. In this study, we aim to establish the age- and sex-related reference intervals of $\mathrm{T}$ lymphocyte subsets by singleplatform for the southwest China population using the indirect method with the data resulting from 53,822 cases of periodic health examination individuals in the Laboratory Information System (LIS) of West China Hospital from 2018 to 2020, hoping to provide a reliable judgment criteria for clinical evaluation, diagnosis and treatment.

\section{Materials and methods \\ Subjects}

$\mathrm{T}$ lymphocyte subsets test data of 53,822 healthy individuals were collected from Laboratory Information System of West China Hospital of Sichuan University (a university-affiliated hospital with 4300 beds) from 2018 to 2020. To verify whether our results are applicable to Southwest China, we collected $\mathrm{T}$ lymphocyte subsets test results of 6134 healthy individuals who examined in Zigong First People's Hospital (a municipal hospital in Sichuan Provence) physical examination center with the same detection algorithm from January to June 2021 for the validation of the obtained reference intervals. Among all the $T$ lymphocyte subsets test results $(n=53,822)$ in our hospital, we excluded 14,130 duplicate individuals according to physical examination number, name, and age. Eventually, T lymphocyte subsets test data of 39,692 healthy individuals were included. There are 21,087 males (53.13\%) and 18,605 females (46.87\%) with a median age of 47 years (ranged from 14 to 93 years) (Fig. 1). For the verification population, there are 3482 males (56.77\%) and 2652 females (43.23\%) with a median age of 48 years (ranged from 17 to 85 years). This study protocol was approved by the Ethics Committee of West China Hospital of Sichuan University and Zigong First People's Hospital, and was performed in accordance with the Declaration of Helsinki. All involved participants provided written informed consent. 


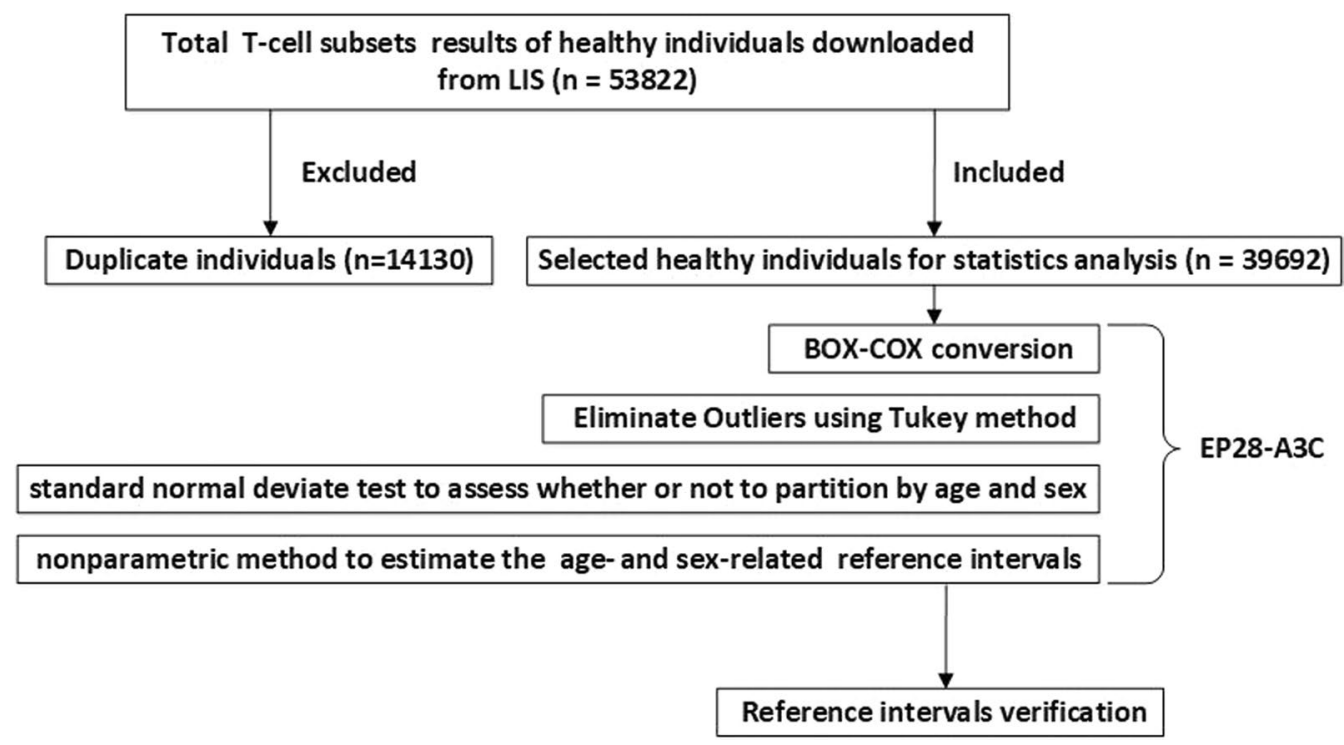

Fig. 1 Diagram showing the establishment of reference intervals for T-cell subsets

\section{Cell preparation, staining, and flow cytometry}

We used FACSCanto II flow cytometer (two lasers, six colors; BD Biosciences, San Jose, CA, USA) with fluorochrome-labeled monoclonal antibodies to confirm the peripheral $\mathrm{T}$ lymphocyte subsets phenotypes. Simultaneously, we used four-color monoclonal antibody combinations (LotID:340,499) to determine the circulating lymphocyte subsets. $9 \mu \mathrm{L}$ of anti-CD45-PerCP/anti-CD3FITC/anti-CD4-APC/anti-CD8-PE reagent was pipetted into the bottom of a Trucount tube. Subsequently, $50 \mu \mathrm{L}$ of heparin anticoagulated peripheral blood was distribute into the tube which were soon afterwards capped and vortexed gently. Incubated at room temperature $\left(20-25{ }^{\circ} \mathrm{C}\right.$ ) for $15 \mathrm{~min}$ in the dark, and drop $500 \mu \mathrm{l}$ of $1 \mathrm{X}$ FACS lysing solution into each tube. The tubes were further incubated for $10 \mathrm{~min}$ in the dark at room temperature $\left(20-25^{\circ} \mathrm{C}\right.$ ) and then analyzed using the flow cytometer. For each sample, a minimum of 1000 events were acquired and analyzed by Cell Quest software. Lymphocytes were identified by their strong CD45 expression and low side scatter. The percentages and absolute counts of $\mathrm{CD} 3+\mathrm{T}$ cells, CD $3+\mathrm{CD} 4+\mathrm{T}$ cells, CD $3+\mathrm{CD} 8+\mathrm{T}$ cells were automatically calculated using BD Multitest software (BD Biosciences). Internal quality-control procedures were carried out to assess instrument parameters and ensure accurate and reproducible enumeration. Daily calibration of the flow cytometer was performed using Calibrite 3 Beads and APC Beads (BD Calibrite ${ }^{\mathrm{TM}}$ ) for optical laser alignment and optimal hydrodynamic focusing settings, respectively. An external quality control procedure was also completed through participation in a performance assessment conducted by the Clinical Inspection Center of the National Health Commission in China. The original source of cell preparation, staining, and flow cytometry were mainly cited from Niu HQ et al. [21].

Reference interval establishment methods and verification The establishment of reference intervals by the indirect method can be roughly summarized into the following 4 steps: (1) Complete sufficient data collection in the hospital database that meets the requirements; (2) Use appropriate methods to transform data with skew distribution; (3) Eliminate outliers or erroneous values in the hospital data; (4) Choose an appropriate method to establish a biological reference interval. First of all, we did the normality test by using the Skewness-Kurtness test. If the skewness value and the kurtosis value are less than 1.96 times the standard deviation, we judged it as a normal distribution. Meanwhile, the Box-Cox transformation was used to transform the non-normally distributed data into approximately normal distribution and Tukey method was used to eliminate outliers. According to the world health organization's (WHO) age division standard and Chinese age division standard, we divided the individuals into subgroups of gender (male and female) and age $(14-30,31-45,46-60,61-75,76-100$ years), and using the standard normal deviate test (z-test) suggested by Harris and Boyd to ascertain whether to divide reference intervals by the subclass. Eventually, we employed the nonparametric method to estimate the $95 \%$ distribution reference intervals of $\mathrm{T}$ lymphocyte subsets. The 
documents of Clinical and Laboratory Standards Institute (CLSI) EP28-A3C [15] were referred (Fig. 1). Furthermore, we collected $\mathrm{T}$ lymphocyte subsets test results of 6134 healthy individuals who examined in Zigong First People's Hospital (a municipal hospital in Sichuan Provence) physical examination center with the same detection algorithm and platform from January to June 2021 for validation. We explored the ratio of verified individuals outside the reference intervals we set up. When the rate was less than $5 \%$, we consider that the reference interval was verified [15].

\section{Statistical analysis}

The data were analyzed by SPSS version 19.0 for Windows (SPSS Inc., Chicago, IL, USA). Continuous data were checked for normal distribution by the SkewnessKurtness test. The z-test were used to determine whether to divide the reference intervals according to the subclass. Using Stata 15.0 statistical software performs BoxCox normality transformation of data (undetermined parameters $\lambda$ are obtained by maximum likelihood method). The Kruskal-Wallis test and Mann-Whitney $\mathrm{U}$ test were used to compare the $\mathrm{T}$ lymphocyte subsets results of differences age and sex. GraphPad Prism 7 was used to make charts. A value of $P<0.05$ was considered statistically significant.

\section{Results}

Distribution of data and elimination of outliers

T-lymphocyte subsets test results are non-normally distributed by the Skewness-Kurtness test. After BOXCOX conversion, they all show an approximately normal distribution (Table 1). We used the Tukey method to eliminate $126,352,417,506,550,444$ cases of outliers and finally obtained 39,566, 39,340, 39,275, 39,186, $39,142,39,248$ reference individuals for CD3 $+\mathrm{T}$ c3ell (\%), CD3 + CD4 + T cell (\%), CD3 + CD8 + T cell (\%), $\mathrm{CD} 3+\mathrm{T}$ cell count (cells/ul), $\mathrm{CD} 3+\mathrm{CD} 4+\mathrm{T}$ cell count (cells/ul), CD3 $+\mathrm{CD} 8+\mathrm{T}$ cell count (cells/ul), respectively (Table 2).

\section{Reference ranges of $T$ lymphocyte subsets}

We grouped the data by gender and age. Z-test results showed that it is necessary to set gender- and agespecific reference ranges by subclass. The levels of $\mathrm{T}$ lymphocyte subsets were significantly different among age and gender groups $(P<0.01$, Table 3$)$. Sex-related $\mathrm{T}$ lymphocyte subsets among the different age groups are shown in Fig. 2. The reference range, median and individual number of $\mathrm{T}$ lymphocyte subsets in different genders and age groups are shown in Tables 3 and 4 respectively.

Table 1 The skewness and kurtosis of T- lymphocyte subsets before and after BOX-COX conversion

\begin{tabular}{llllc}
\hline & \multicolumn{2}{l}{ Before BOX-COX conversion } & & \multicolumn{2}{c}{ After BOX-COX conversion } \\
\cline { 2 - 3 } & Skewness & Kurtosis & & Skewness \\
\hline CD3+T cell (\%) & -0.668 & 0.821 & -0.057 & Kurtosis \\
CD3+CD4+T cell (\%) & 0.115 & 0.094 & -0.001 & -0.208 \\
CD3+CD8+T cell (\%) & 2.899 & 104.937 & -0.007 & 1.234 \\
CD3+T cell count (cells/ul) & 1.084 & 2.751 & -0.003 & 0.411 \\
CD3+CD4+T cell count (cells/ul) & 1.254 & 3.496 & -0.008 & 0.538 \\
CD3+CD8+T cell count (cells/ul) & 1.665 & 7.092 & -0.021 & 0.322 \\
\hline
\end{tabular}

Table $2 \lambda$ value for BOX-COX conversion and number of eliminated outliers use Tukey method in T-cell subsets

\begin{tabular}{llll}
\hline & $\boldsymbol{\lambda}$ & N of outliers & $\begin{array}{c}\text { N of individuals } \\
\text { eventually } \\
\text { included }\end{array}$ \\
\hline CD3+T cell (\%) & & 126 & 39,566 \\
CD3+CD4+T cell (\%) & 2.450906 & 352 & 39,340 \\
CD3+CD8+T cell (\%) & 0.828792 & 417 & 39,275 \\
CD3+T cell count (cells/ul) & 0.309667 & 506 & 39,186 \\
CD3+CD4+T cell count (cells/ul) & 0.1329571 & 550 & 39,142 \\
CD3+CD8+T cell count (cells/ul) & 0.1203612 & 444 & 39,248 \\
\hline
\end{tabular}




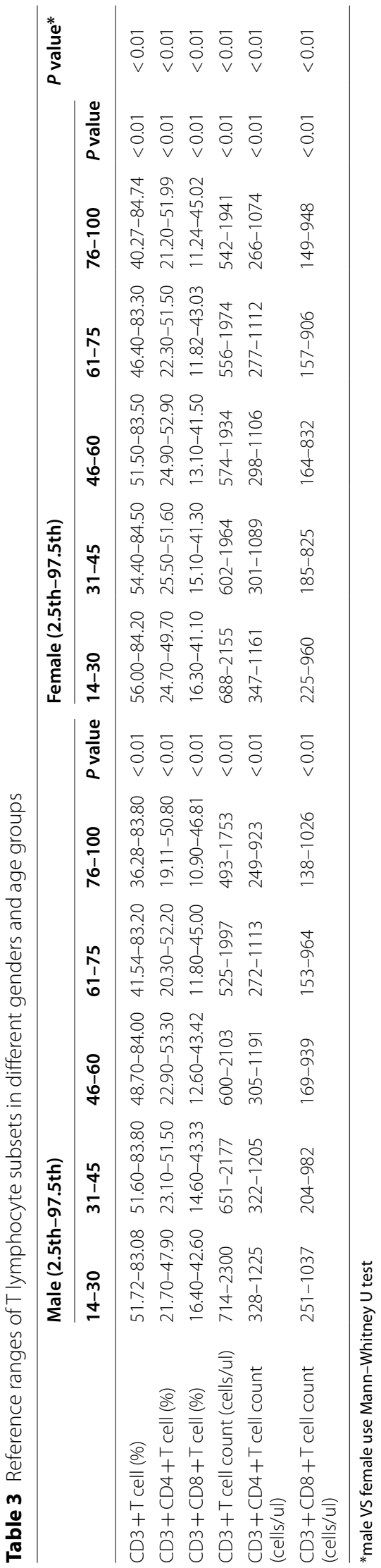




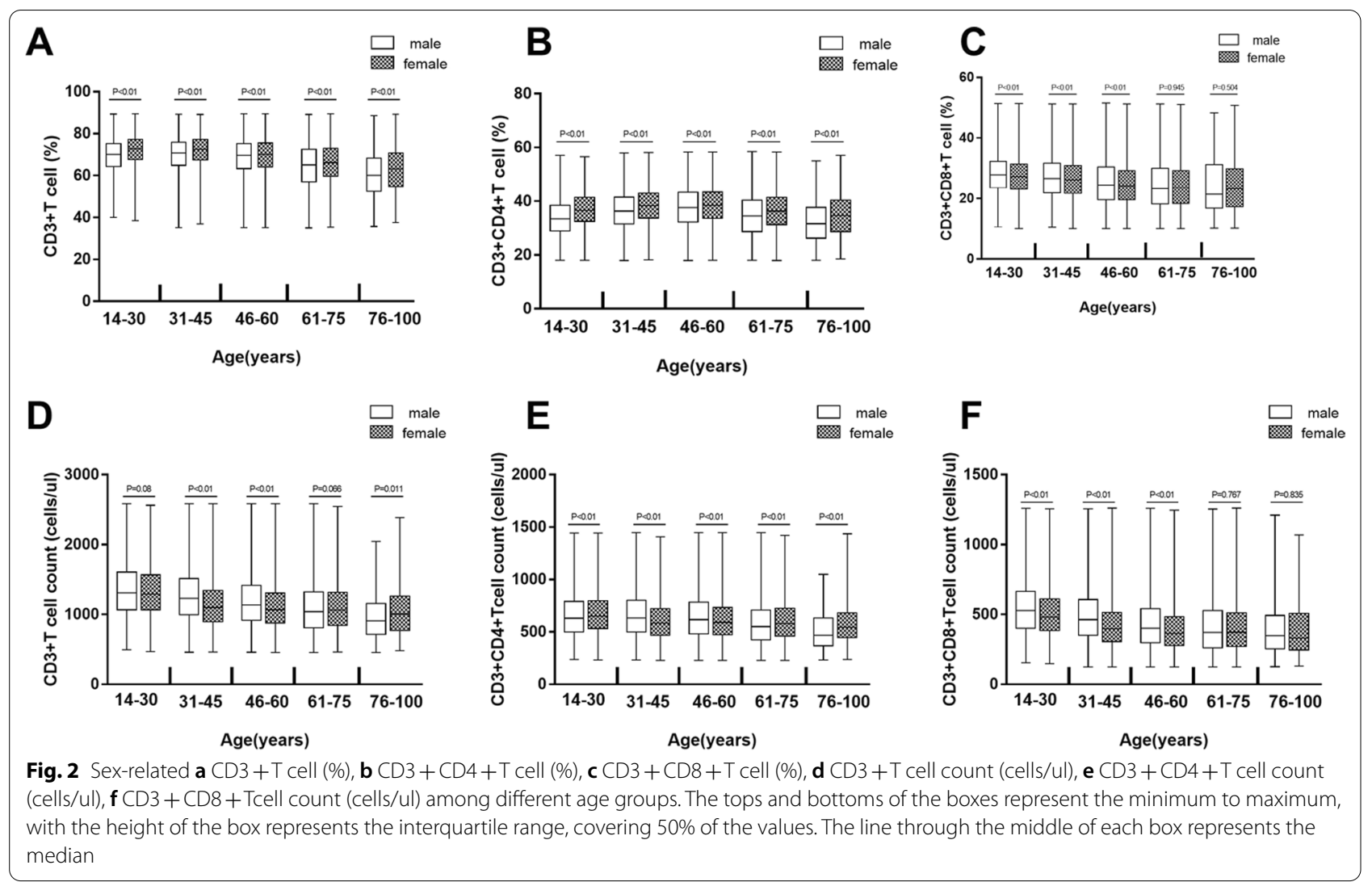

\section{Correlation between $\mathrm{T}$ lymphocyte subsets and age in different sex groups}

The correlation coefficients between $\mathrm{CD} 3+\mathrm{T}$ cell (\%), $\mathrm{CD} 3+\mathrm{CD} 4+\mathrm{T}$ cell (\%), $\mathrm{CD} 3+\mathrm{CD} 8+\mathrm{T}$ cell (\%), $\mathrm{CD} 3+\mathrm{T}$ cell count (cells/ul), $\mathrm{CD} 3+\mathrm{CD} 4+\mathrm{T}$ cell count (cells/ul), CD3 $+\mathrm{CD} 8+\mathrm{T}$ cell count (cells/ul) and age were $-0.150,0.036,-0.174,-0.208,-0.110,-0.234$ in male and $-0.241,-0.015,-0.185,-0.161,-0.071$, -0.189 in female (Fig. 3). The slopes for $\mathrm{CD} 3+\mathrm{T}$ cell (\%), $\mathrm{CD} 3+\mathrm{CD} 4+\mathrm{T}$ cell (\%), $\mathrm{CD} 3+\mathrm{CD} 8+\mathrm{T}$ cell $(\%)$, $\mathrm{CD} 3+\mathrm{T}$ cell count (cells/ul), $\mathrm{CD} 3+\mathrm{CD} 4+\mathrm{T}$ cell count (cells/ul), CD3 $+\mathrm{CD} 8+\mathrm{T}$ cell count (cells/ul) were $-0.14,0.01,-0.10,-6.85,-2.15,-3.51$ in male and $-0.17,-0.01,-0.09,-4.75,-1.27,-2.34$ in female (Additional file 1: Table S2), which are more obvious in male and absolute counting.

\section{Verification and comparison of reference intervals}

According to the reagent specification, the T lymphocyte subsets reference intervals currently in use were 66.90 83.10, 33.19-47.85, 20.40-34.70, 941-2226, 471-1220, 303-1003 for CD3 + T cell (\%), CD3 + CD4 + T cell (\%), $\mathrm{CD} 3+\mathrm{CD} 8+\mathrm{T}$ cell $(\%), \mathrm{CD} 3+\mathrm{T}$ cell count (cells/ul), $\mathrm{CD} 3+\mathrm{CD} 4+\mathrm{T}$ cell count (cells/ul), $\mathrm{CD} 3+\mathrm{CD} 8+\mathrm{T}$ cell count (cells/ul) respectively, regardless of the age and sex. Although the ratios of verification individuals outside the reference intervals by indirect method were partly less than $5 \%$ account for the limited sample size in different gender and age groups (Fig. 4a and b), compared with the reference intervals derived from the reagent specification currently in use, it has been greatly improved (Fig. $4 \mathrm{c}$ and d). There was a statistically significant difference in the ratio of positive judgments between different reference intervals in the verification population $(P<0.01)$.

\section{Discussion}

Appropriate and reliable reference ranges of $\mathrm{T}$ lymphocyte subsets adapted to local population are essential for the immune status evaluation of patients with immunological diseases. In the present study, the single-platform method was used to calculate the absolute number of lymphocyte subgroups (Quantitative microspheres detect the number of lymphoid subsets). This method can directly measure the number of cells, and the result is more objective and accurate, without the error caused by different methods of instrument. We initially evaluated the sex- and age-related reference ranges of $\mathrm{CD} 3+\mathrm{T}$ cell $(\%), \mathrm{CD} 3+\mathrm{CD} 4+\mathrm{T}$ cell (\%), $\mathrm{CD} 3+\mathrm{CD} 8+\mathrm{T}$ cell $(\%), \mathrm{CD} 3+\mathrm{T}$ cell count (cells/ul), 


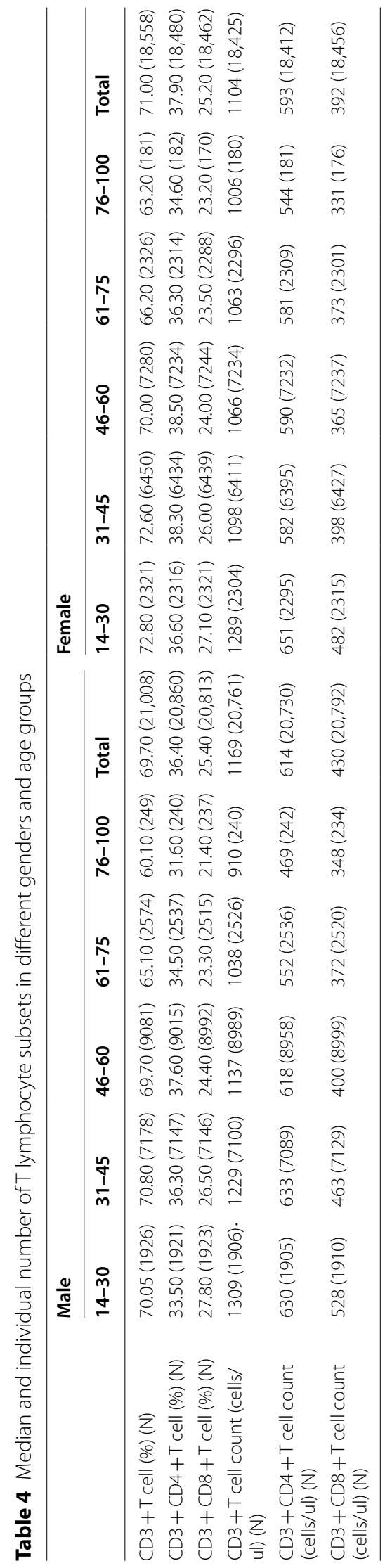




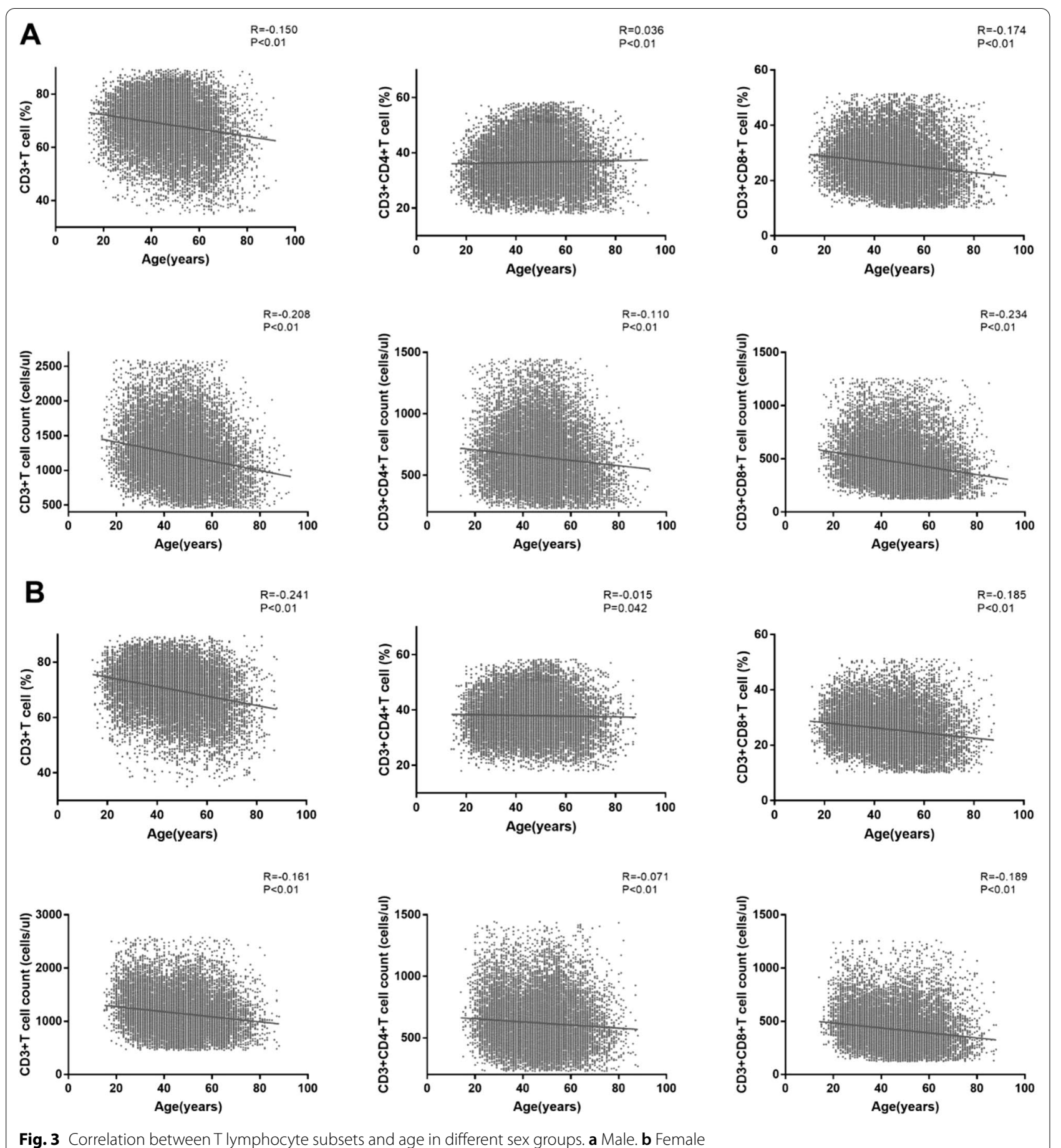

Fig. 3 Correlation between T lymphocyte subsets and age in different sex groups. a Male. b Female

$\mathrm{CD} 3+\mathrm{CD} 4+\mathrm{T}$ cell count (cells/ul), CD3 $+\mathrm{CD} 8+\mathrm{T}$ cell count (cells/ul) using flow cytometry among healthy population in southwest China by indirect method with a large sample size of 39,692 healthy individuals, which facilitated the interpretation of research results and clinical decision-making. Based on our research, we found that the reference ranges of $\mathrm{T}$ lymphocyte subsets by single-platform in different ages and genders are significantly different. Additionally, we further demonstrated the absolute count of $\mathrm{CD} 3+\mathrm{T}$ cell, $\mathrm{CD} 3+\mathrm{CD} 4+\mathrm{T}$ cell, $\mathrm{CD} 3+\mathrm{CD} 8+\mathrm{T}$ cell decreased with aging. 

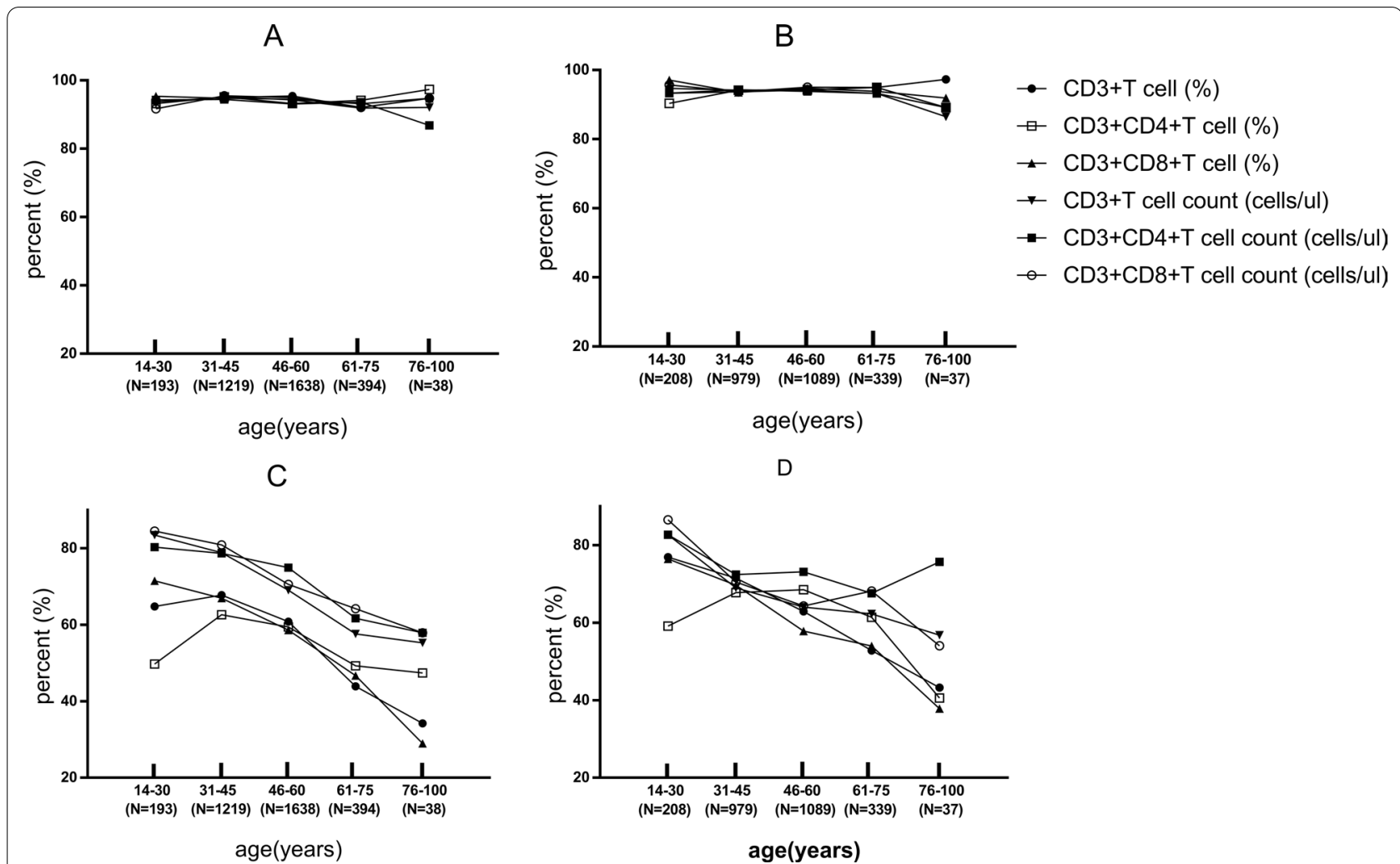

Fig. 4 The verifying of T lymphocyte subsets reference intervals by indirect method (a: male and $\mathbf{b}$ : female) and the reagent specification (c: male and $\mathbf{d}$ female). The percent (\%) means the ratios of verification individuals inside the reference intervals of different age groups and genders

The documents CLSI EP28-A3C recommends the direct method to establish the reference intervals. Nevertheless, the difference in screening criteria and the existence of subclinical status of the disease will directly affect the value of the reference intervals. On account of the direct method is complicated, time-consuming, and expensive, most laboratories directly quote the biological reference intervals recommended by the reagent manufacturer, which may not be suitable for the local population. With the development of information technology, utilizing the large amount of data stored in the LIS to establish a biological reference interval based on mathematical statistics (indirect method) has also been accepted by EP28-A3C and used in many studies [24, 25]. The "indirect" method was proposed 50 years ago [24]. This method is used when it is deemed too difficult to collect samples from healthy subjects (eg, pediatrics). In many studies, data from all hospital patients (or all outpatients) are used to estimate reference intervals, but this method is perhaps more appropriately employed using data from individuals who are relatively healthy [15]. The advantages of the indirect method are mainly in two points: (1) There are sufficient and reliable data sources; (2) The operation of the indirect method is simpler than the direct method, time-saving, and low-cost, which is conducive to the establishment and regular review of reference intervals [15]. In this study, we utilized indirect method to establish the sex- and age-related nonparametric reference ranges of $\mathrm{T}$ lymphocyte subsets among healthy population in southwest China. Our results show that the reference ranges of $\mathrm{T}$ lymphocyte subsets need to be divided by age and gender. The older the age, the lower the absolute count of $\mathrm{T}$ lymphocyte subsets in both male and female, which is in consistent with Tang GX et al.s research [20]. Niu HQ et al. [21] reported that the $2.5 \%$ to $97.5 \%$ reference range of percentages (absolute counts, cells $/ \mu \mathrm{l}) \mathrm{CD} 3+\mathrm{CD} 4+\mathrm{T}$ cells in 150 healthy volunteers aged 20-70 years was $23.78 \%-51.07 \%(360-1127)$ in Shanxi Province, North China. The $2.5 \%$ to $97.5 \%$ reference ranges of percentages (absolute counts, cells $/ \mu \mathrm{l}$ ) $\mathrm{CD} 3+\mathrm{T}$ cells, $\mathrm{CD} 3+\mathrm{CD} 4+\mathrm{T}$ cells, $\mathrm{CD} 3+\mathrm{CD} 8+\mathrm{T}$ cells in Tang GX et al. 's research [20] and Qin L et al. 's research [19] are shown in Additional file 1: Table S1. Our results are similar with Niu HQ et al. [21] and Tang GX et al. [20] but slightly different from Qin L et al. [19]. The discrepancy may be explained by different sample size, indirect method we used to establish reference value and the variance of ethnic groups. Simultaneously, we found 
the reference ranges of $\mathrm{T}$ lymphocyte subsets should be differentiated by ages and genders, using the standard normal deviate test (z-test) suggested by Harris and Boyd according to CLSI EP28-A3C, which is more scientific.

Meanwhile, our results are quite different from those of people in other regions of the world such as South Florida [26], Qatari [27], Omani [28], Ethiopia [18] and German [29]. It seems that the differences in statistical methods (direct or indirect, nonparametric or parametric), detecting platforms (dual or single), instruments as well as genetic, nutrition and environmental variations between populations in different area might result in the discrepancies in lymphocyte subsets, which further illustrated that region reference ranges for lymphocyte subsets were necessary.

According to our results, compared with male, the reference ranges of $\mathrm{CD} 3+\mathrm{T}$ cell $(\%), \mathrm{CD} 3+\mathrm{CD} 4+\mathrm{T}$ cell (\%), $\mathrm{CD} 3+\mathrm{CD} 8+\mathrm{T}$ cell (\%), $\mathrm{CD} 3+\mathrm{CD} 8+\mathrm{T}$ cell count were narrower in the whole age groups of female, while the reference ranges of $\mathrm{CD} 3+\mathrm{T}$ cell count, $\mathrm{CD} 3+\mathrm{CD} 4+\mathrm{T}$ cell count were narrower in $\leq 75$ years old groups and wider in the 76-100 age group of female (Additional file 1: Table S3). Meanwhile, in agreement with Qin $\mathrm{L}$ et al. [19], higher median values of CD3 + T cell (\%), $\mathrm{CD} 3+\mathrm{CD} 4+\mathrm{T}$ cell (\%) were observed in the whole age groups of female, while the median values of $\mathrm{CD} 3+\mathrm{CD} 8+\mathrm{T}$ cell count were higher in every age groups of male. The median values of $\mathrm{CD} 3+\mathrm{CD} 8+\mathrm{T}$ cell (\%), $\mathrm{CD} 3+\mathrm{T}$ cell count were higher in $\leq 60$ years old groups and lower in $>60$ years old groups in male. Nevertheless, the median values of $\mathrm{CD} 3+\mathrm{T}$ cell (\%), $\mathrm{CD} 3+\mathrm{CD} 4+\mathrm{T}$ cell (\%), $\mathrm{CD} 3+\mathrm{CD} 8+\mathrm{T}$ cell (\%), $\mathrm{CD} 3+\mathrm{T}$ cell count, $\mathrm{CD} 3+\mathrm{CD} 4+\mathrm{T}$ cell count, $\mathrm{CD} 3+\mathrm{CD} 8+\mathrm{T}$ cell count fall by $9.95 \%, 1.90 \%, 6.40 \%$, $30.48 \%, 25.56 \%, 34.09 \%$ between the extremes of age in male and $9.6 \%, 2.00 \%, 3.90 \%, 21.96 \%, 16.44 \%, 31.33 \%$ in female (Additional file 1: Table S4), which is more marked in men and absolute counting. According to the absolute values of slopes for $\mathrm{T}$ lymphocyte subsets in both male and female, we discovered that the absolute values were higher in male, and compared with relative values of $\mathrm{T}$ lymphocyte count, absolute counting dropped even more dramatically. We concluded that the total lymphocyte in the peripheral blood decreases with age relatively in parallel with the absolute counting of $\mathrm{T}$ lymphocyte decrease, which resulted in an unobviously decrease in the percentage of $\mathrm{T}$ lymphocytes. Contemporaneously, $\mathrm{CD} 3+\mathrm{CD} 8+\mathrm{T}$ cell count decreased most obviously and faster than $\mathrm{CD} 3+\mathrm{CD} 4+\mathrm{T}$ cell count in both male and female. These differences may be explained by different hormonal effects [26] and age-related thymic involution [19], which confirmed the influence of sex and age on peripheral lymphocyte subsets.
Accumulating evidence have suggested sex differences in immune responses [30,31]. Sex hormones play a major role in shaping $\mathrm{T}$ cell responses through controlling gene expression in thymic epithelial cells and regulating innate immune cells [30]. For instance, higher estrogen levels in female drive increased T cell IFN- $\gamma$ production and predispose female to IFN- $\gamma$-mediated autoimmune conditions. Androgen/androgen receptor complexes can directly induce anti-inflammatory IL-10 expression by $\mathrm{CD} 4+\mathrm{T}$ cells, which has been proposed to underlie male protection from central nervous system (CNS) autoimmunity [30]. The broad spectrum of changes affecting the immune system in old age are known as immunosenescence. One of the major causes of immunosenescence of $\mathrm{T}$ cells is the involution of the thymus $[32,33]$. The rate of thymic T-cell output (around $2 \times 10^{6}$ cells per day at the peak) declines over time, with an estimated half-life of about 16 years in humans [34]. The frequency of naïve $T$ cells is reduced in the periphery and in lymphoid organs in old age, particularly within the CD8 $+\mathrm{T}$ cell compartment. The composition of the $\mathrm{CD} 4+\mathrm{T}$ cell compartment is more stable during aging and it has been described that homeostatic control mechanisms maintain a relatively large and diverse pool of naïve $\mathrm{CD} 4+\mathrm{T}$ cells, which only changes substantially in very old age [32]. This may explain CD3 $+\mathrm{CD} 8+\mathrm{T}$ cell count decreased most obviously and faster than $\mathrm{CD} 3+\mathrm{CD} 4+\mathrm{T}$ cell count between the extremes of age in both male and female. In consequence, the sex- and age-related peripheral T lymphocyte subsets differences may be explained by sex hormones discrepancy and age-related thymic involution.

In our study, the correlation coefficients between $\mathrm{CD} 3+\mathrm{T}$ cell (\%), $\mathrm{CD} 3+\mathrm{CD} 4+\mathrm{T}$ cell (\%), $\mathrm{CD} 3+\mathrm{CD} 8+\mathrm{T}$ cell $(\%), \mathrm{CD} 3+\mathrm{T}$ cell count (cells/ul), $\mathrm{CD} 3+\mathrm{CD} 4+\mathrm{T}$ cell count (cells/ul), CD3 $+\mathrm{CD} 8+\mathrm{T}$ cell count (cells/ul) and age were $-0.150,0.036$, $-0.174,-0.208,-0.110,-0.234$ in male and -0.241 , $-0.015,-0.185,-0.161,-0.071,-0.189$ in female. According to Niu HQ et al. [21], the correlation coefficients between CD3 $+\mathrm{CD} 4+\mathrm{T}$ cell (\%) and age is 0.294 . Tang GX et al. [20] reported the correlation coefficients between $\mathrm{CD} 3+\mathrm{T}$ cell (\%), $\mathrm{CD} 3+\mathrm{CD} 4+\mathrm{T}$ cell (\%), $\mathrm{CD} 3+\mathrm{CD} 8+\mathrm{T}$ cell $(\%), \mathrm{CD} 3+\mathrm{T}$ cell count (cells/ul), $\mathrm{CD} 3+\mathrm{CD} 4+\mathrm{T}$ cell count (cells/ul), CD3 $+\mathrm{CD} 8+\mathrm{T}$ cell count (cells/ul) and age were $-0.318,0.129$, $-0.391,-0.656,-0.555,-0.624$ without regard to gender. Qin L et al. [19] found that the correlation coefficients between $\mathrm{CD} 3+\mathrm{T}$ cell count (cells/ul), $\mathrm{CD} 3+\mathrm{CD} 4+\mathrm{T}$ cell count (cells/ul), CD3 $+\mathrm{CD} 8+\mathrm{T}$ cell count (cells/ul) and age were $-0.103,-0.175$, -0.154 . Our results are similar with Niu HQ et al. [21] and Qin L et al. [19] but slightly different from Tang GX et al. [20]. The percent of CD3 + T cell, CD3 + CD8 + T 
cell and the numbers of CD3 $+\mathrm{T}$ cell count (cells/ul), $\mathrm{CD} 3+\mathrm{CD} 4+\mathrm{T}$ cell count (cells/ul), CD3 $+\mathrm{CD} 8+\mathrm{T}$ cell count (cells/ul) were all weak negatively correlated with age in both male and female $(P<0.01)$, while the percent of $\mathrm{CD} 3+\mathrm{CD} 4+\mathrm{T}$ cell was weak positively correlated with age in male but weak negatively in female $(P<0.01)$. The reason needs to be further studied.

The ratios of verification individuals outside the reference intervals derived from the reagent specification currently in use according to the reagent specification were $13.46-71.05 \%$, which will cause overdiagnosis and excessive intervention, causing unnecessary psychological burden and economic burden on the individuals. Moreover, as the age increases, the ratios in the reference interval decreases in both male and female, which further illustrates we should divide the reference interval by age. The ratios of verification individuals outside the reference intervals established by indirect method were $2.88-13.51 \%$. it has been greatly improved and was superior to the reference intervals currently in use.

This study has several limitations. Firstly, the indirect method used in this study has specific restrictions for the inclusion and exclusion of reference individuals and may include some non-healthy individuals. Secondly, due to the limited experimental conditions, we cannot do more analysis of lymphocyte subpopulations such as B and NK lymphocyte. Finally, according to Tang GX et al. [20] and Qin L et al. [19], the increase of function in CD4+ and CD8 $+\mathrm{T}$ cells with increasing age is to maintain certain degree of immune function, as the numbers of CD4 + and CD8 $+\mathrm{T}$ cells have been declining during life. Moreover, Niu HQ et al. [21] and Togashi Y et al. [35] reported that the abundance of Treg cells in the peripheral blood tends to increase with aging. Botafogo V et al. [36] and Garcia-Prat M et al. [37] expounded that naïve $\mathrm{CD} 4+\mathrm{T}$ cells tended to decrease with age, in parallel with the reduction in thymic function. Nevertheless, we have not tested the $\mathrm{CD} 4+\mathrm{T}$ cell subpopulations and the function of $\mathrm{CD} 4+$ and $\mathrm{CD} 8+\mathrm{T}$ cells, which is warranted in our further studies.

In conclusion, we initially established the reference ranges of $\mathrm{T}$ lymphocyte subsets by single-platform among healthy population in southwest China by indirect method. We found that the reference ranges of $\mathrm{T}$ lymphocyte subsets by single-platform should be differentiated by ages and genders. Additionally, we further demonstrated the absolute count of $\mathrm{CD} 3+\mathrm{T}$ cell, $\mathrm{CD} 3+\mathrm{CD} 4+\mathrm{T}$ cell, $\mathrm{CD} 3+\mathrm{CD} 8+\mathrm{T}$ cell decreased with aging. The age-related decreasing is more marked in men and $\mathrm{CD} 3+\mathrm{CD} 8+\mathrm{T}$ cell count.
Abbreviations

LIS: Laboratory information system; HIV: Human immunodeficiency virus; IQR: Interquartile range; WHO: World health organization; CLSI: Clinical \& laboratory standards institute; IFN-ץ: Interferon Y; IL-10: Interleukin 10.

\section{Supplementary Information}

The online version contains supplementary material available at https://doi. org/10.1186/s12865-021-00474-0.

Additional file 1. Supplement Table 1-Table 4.

Acknowledgements

We appreciated for LIS staff for providing us the data for the manuscript.

\section{Authors' contributions}

$B W$ and $Y G$ performed the data analyses and wrote the manuscript; $L Z, H Z$ and WL provided and analyzed the data required for validation; $\mathrm{QM}$ and $\mathrm{LY}$ helped perform the analysis with constructive discussions; QN, WL and YL contributed to the conception of the study and revised the manuscript. YB and WF helped me look up relevant literatures and check the data and related calculations during the revision process. All authors read and approved the final manuscript.

\section{Funding}

This study was supported by 1·3.5 Project for Incubation (No. 19HXFH023), Science and Technology Agency of Sichuan Province (2019YFS0287, 2020YFS0228, 2021YFS0160)

\section{Availability of data and materials}

The datasets generated and/or analysed during the current study are not publicly available due our hospital doesn't allow us to upload raw data on large numbers of patients (we can provide the results of the statistical process if necessary) but are available from the corresponding author on reasonable request.

\section{Declarations}

Ethics approval and consent to participate

This study protocol was approved by the Ethics Committee of West China Hospital of Sichuan University and Zigong First People's Hospital, and was performed in accordance with the Declaration of Helsinki. All involved participants provided written informed consent. For minor participants, informed consent is obtained from parents and/or legal guardian.

\section{Consent for publication}

Not applicable.

\section{Competing interests}

The authors declare that they have no competing interests.

\section{Author details}

${ }^{1}$ Department of Laboratory Medicine/Clinical Research Center of Laboratory Medicine, West China Hospital, Sichuan University, 37 Guo Xue Xiang, Chengdu 610041, Sichuan Province, China. ${ }^{2}$ West China Second University Hospital/West China Women's and Children's Hospital, Key Laboratory of Birth Defects and Related Diseases of Women and Children, Sichuan University, No. 20, Section 3, Renmin South Road, Wuhou District, Chengdu 610041, Sichuan Province, China. ${ }^{3}$ Department of Laboratory Medicine, Zigong First People's Hospital, Zigong, Sichuan Province, China.

Received: 8 August 2021 Accepted: 13 December 2021

Published online: 20 December 2021 


\section{References}

1. Kumar BV, Connors TJ, Farber DL. Human T cell development, localization, and function throughout life. Immunity. 2018;48(2):202-13.

2. Gaud G, Lesourne R, Love PE. Regulatory mechanisms in T cell receptor signalling. Nat Rev Immunol. 2018;18(8):485-97.

3. Thommen DS, Schumacher TN. T cell dysfunction in cancer. Cancer Cell. 2018;33(4):547-62.

4. Gu Y, Jin Y, Ding J, et al. Low absolute CD4(+)T cell counts in peripheral blood predict poor prognosis in patients with newly diagnosed multiple myeloma. Leuk Lymphoma. 2020;61(8):1869-76.

5. Manasanch EE, Gertz MA. Exhausted and outnumbered: CD4+ T cells in the myeloma battlefield. Leuk Lymphoma. 2020;61(8):1777-9.

6. Cao $X$, Kong YL, Wang $L$, et al. Circulating low CD4(+)/CD8(+) ratio is associated with poor prognosis in Waldenstrom macroglobulinemia patients. Ann Hematol. 2021;100(4):995-1002.

7. Zhang $X Y, X u$ J, Zhu HY, et al. Negative prognostic impact of low absolute CD4(+) T cell counts in peripheral blood in mantle cell lymphoma. Cancer Sci. 2016;107(10):1471-6.

8. Arneth B. Activated CD4+ and CD8+ T cell proportions in multiple sclerosis patients. Inflammation. 2016:39(6):2040-4.

9. McBride JA, Striker R. Imbalance in the game of T cells: What can the CD4/CD8 T-cell ratio tell us about HIV and health? PLoS Pathog 2017; 13(11): e1006624

10. Wu TD, Madireddi S, de Almeida PE, et al. Peripheral T cell expansion predicts tumour infiltration and clinical response. Nature. 2020;579(7798):274-8.

11. Helleberg M, Kronborg G, Ullum H, et al. Course and Clinical Significance of CD8 + T-Cell Counts in a Large Cohort of HIV-Infected Individuals. J Infect Dis. 2015;211(11):1726-34

12. Wing JB, Tanaka A, Sakaguchi S. Human FOXP3(+) regulatory T cell heterogeneity and function in autoimmunity and cancer. Immunity. 2019;50(2):302-16.

13. Glatzova D, Cebecauer M. Dual role of CD4 in peripheral T lymphocytes. Front Immunol. 2019;10:618.

14. Zander R, Schauder D, Xin G, et al. CD4(+) T cell help Is required for the formation of a cytolytic CD8(+) T cell subset that protects against chronic infection and cancer. Immunity. 2019;51(6):1028-42.

15. CLSI. Defining, Establishing, and Verifying Reference Intervals in the Clinical Laboratory; Approved Guideline-Third Edition. CLSI document EP28 - A3c ed Wayne, PA, USA: CLSI (Clinical Laboratory Standards Institute). 2010.

16. Adoga MP, Pennap GR, John PA, et al. CD4- and CD3-T lymphocyte reference values of immunocompetent urban and rural subjects in an African nation. Scand J Immunol. 2012;76(1):33-8.

17. Lerkvaleekul B, Apiwattanakul N, Klinmalai C, et al. Age-related changes in lymphocyte subpopulations in healthy Thai children. J Clin Lab Anal. 2020:34(5):e23156.

18. Mulu W, Abera B, Mekonnen Z, et al. Haematological and CD4+ T cells reference ranges in healthy adult populations in Gojjam zones in Amhara region, Ethiopia. PLoS One. 2017;12(7):e0181268.

19. Qin L, Jing X, Qiu ZF, et al. Aging of immune system: Immune signature from peripheral blood lymphocyte subsets in 1068 healthy adults. Aging. 2016:8(5):848-59.

20. Tang GX, Yuan X, Luo Y, et al. Establishing immune scoring model based on combination of the number, function, and phenotype of lymphocytes. Aging. 2020;12(10):9328-43.

21. Niu HQ, Zhao XC, Li W, et al. Characteristics and reference ranges of CD4(+)T cell subpopulations among healthy adult Han Chinese in Shanxi Province, North China. BMC Immunol. 2020;21(1):44.

22. Jia L, Li J, Zhang Y, et al. Age- and sex-related reference intervals of lymphocyte subsets in healthy ethnic Han Chinese children. Cytometry A. 2015:87(12):1116-26.

23. Zhang $X$, Ding $Y$, Zhang $Y$, et al. Age- and sex-specific reference intervals for hematologic analytes in Chinese children. Int J Lab Hematol. 2019;41(3):331-7.

24. Lo Sasso B, Vidali M, Scazzone C, et al. Reference interval by the indirect approach of serum thyrotropin (TSH) in a Mediterranean adult population and the association with age and gender. Clin Chem Lab Med. 2019;57(10):1587-94.

25. Zierk J, Arzideh F, Haeckel R, et al. Pediatric reference intervals for alkaline phosphatase. Clin Chem Lab Med. 2017;55(1):102-10.
26. Valiathan $R$, Deeb K, Diamante M, et al. Reference ranges of lymphocyte subsets in healthy adults and adolescents with special mention of T cell maturation subsets in adults of South Florida. Immunobiology. 2014;219:487-96.

27. Al-Thani A, Hamdi WS, Al-Marwani A, et al. Reference ranges of lymphocyte subsets in healthy Qatari adults. Biomark Med. 2015;9(5):443-52.

28. Al-Mawali A, Pinto AD, Al Busaidi R, et al. Lymphocyte subsets: reference ranges in an age- and gender-balanced population of Omani healthy adults. Cytometry A. 2013;83(8):739-44.

29. Jentsch-Ullrich K, Koenigsmann M, Mohren M, et al. Lymphocyte subsets' reference ranges in an age- and gender-balanced population of 100 healthy adults-a monocentric German study. Clin Immunol. 2005;116(2):192-7.

30. Brown MA, Su MA. An Inconvenient Variable: Sex Hormones and Their Impact on T Cell Responses. J Immunol. 2019;202(7):1927-33.

31. Aldridge J, Pandya JM, Meurs $L$, et al. Sex-based differences in association between circulating $T$ cell subsets and disease activity in untreated early rheumatoid arthritis patients. Arthritis Res Ther. 2018;20(1):150.

32. Pangrazzi L, Weinberger B. T cells, aging and senescence. Exp Gerontol 2020; 134: 110887

33. Li M, Yao D, Zeng $X$, et al. Age related human T cell subset evolution and senescence. Immun Ageing. 2019;16:24.

34. Minato N, Hattori M, Hamazaki Y. Physiology and pathology of T-cell aging. Int Immunol. 2020;32(4):223-31.

35. Togashi Y, Shitara K, Nishikawa H. Regulatory T cells in cancer immunosuppression-implications for anticancer therapy. Nat Rev Clin Oncol. 2019:16:356-71.

36. Botafogo V, Perez-Andres M, Jara-Acevedo M, et al. Age distribution of multiple functionally relevant subsets of CD4+ T cells in human blood using a standardized and validated 14-Color euroflow immune monitoring tube. Front Immunol. 2020;11:166.

37. Garcia-Prat M, Alvarez-Sierra D, Aguilo-Cucurull A, et al. Extended immunophenotyping reference values in a healthy pediatric population. Cytometry B Clin Cytom. 2019;96(3):223-33.

\section{Publisher's Note}

Springer Nature remains neutral with regard to jurisdictional claims in published maps and institutional affiliations.

Ready to submit your research? Choose BMC and benefit from

- fast, convenient online submission

- thorough peer review by experienced researchers in your field

- rapid publication on acceptance

- support for research data, including large and complex data types

- gold Open Access which fosters wider collaboration and increased citations

- maximum visibility for your research: over $100 \mathrm{M}$ website views per year

At BMC, research is always in progress.

Learn more biomedcentral.com/submissions 